УДК 006.91:681.2

О. В. ТОМАШЕВСЬКИЙ ${ }^{1}$, В. У. ІГНАТКІН ${ }^{2}$, Г. В. СНІЖНОЙ ${ }^{1}$

1 Запорізький національний технічний університет, Запоріжжжя, Украӥна

${ }^{2}$ Дніпровський державний технічний університет, Кам'янське, Украйна

\title{
ДОСЛІДЖЕННЯ ВПЛИВУ НА НАДІЙНІСТЬ ЗАСОБІВ ВИМІРЮВАЛЬНОЇ ТЕХНІКИ ПАРАМЕТРІВ СИСТЕМИ МЕТРОЛОГІЧНОГО ОБСЛУГОВУВАННЯ
}

\begin{abstract}
Розглянуто організація виробництва і модель системи метрологічного обслуговування засобів вимірювальної техніки (МО ЗВТ) на промислових підприємствах з складними технологічними прочесами. Визначені показники технічної й метрологічної надійності. Показано вплив оптимального вибору значень параметрів системи метрологічного обслуговування на зменшення втрат від виробництва бракованої продукиії. Одержані залежності показників надійності засобів вимірювальної техніки від основних параметрів МО ЗВТ. Запропоновані рекомендації практичного використання результатів дослідження для підприємств, де виготовляється складна продукція, зокрема при виробництві авіаційно-космічної техніки.
\end{abstract}

Ключові слова: вимірювальна техніка, система метрологічного обслуговування, модель метрологічного обслуговування, метрологічна надійність, технічна надійність, управління якістю продукції

\section{Вступ}

Рішення задач оцінки й контролю надійності засобів вимірювальної техніки (ЗВТ) повинно підлягати головній задачі самого виробництва - забезпечити необхідний об'єм випуску виробів при мінімальних витратах. Надійність ЗВТ можна умовно розділити на технічну і метрологічну надійність. До основних комплексних показників технічної надійності ЗВТ [1] відносять коефіцієнт готовності - К коефіцієнт технічного використання - $\mathrm{K}_{\mathrm{TB}}$. Для характеристики вірогідності (достовірності) показань ЗВТ застосовується коефіцієнт вірогідності - К Метрологічна надійність - це властивість до збереження працездатного стану ЗВТ упродовж деякого часу. Метрологічна надійність ЗВТ визначається такими характеристик відмов, як: $\mathrm{T}_{\text {я }}$ середня наробка (напрацювання) на явну відмову; $\mathrm{T}_{\mathrm{c}}$ - середня наробка на сховану відмову; $\mathrm{T}_{\mathrm{p}}$ - середнє напрацювання на ремонт.

Метрологічне обслуговування засобів вимірювальної техніки (МО ЗВТ) можна розглядати як підсистему, що забезпечує систему управління якістю продукції виробничого процесу [1]. Склад, структуpa i стратегія керування цією підсистемою визначають витрати, пов'язані з ії утриманням на виробництві, а також витрати, викликані випуском бракованої продукції через застосування несправних ЗВТ. Чим краще працює МО ЗВТ, тим нижчі витрати від браку, але вищі витрати на утримування МО ЗВТ, і навпаки. Ефективне функціонування МО ЗВТ забезпе- чується оптимальним вибором значень параметрів ЗВТ для мінімізації втрат від виробництва бракованої продукції й витрат на утримування МО ЗВТ.

Підсистеми МО ЗВТ направлені на виявлення браку в готовій продукції і на перевірку якості виробу в процесі його виготовлення. Для забезпечення високої якості продукції необхідно висока надійність МО ЗВТ. Для рішення цієї задачі, перш за все, потрібно визначити вплив параметрів підсистеми МО ЗВТ на їх надійність.

Питання формалізації процесів МО ЗВТ і зв'язок показників технічної надійності і параметрів системи метрологічного обслуговування розглянуті в [2].

В роботі [3] одержані вирази, які дозволяють визначити значення коректувань міжповірочного інтервалу в процесі експлуатації ЗВТ за їх поточним станом, що дозволяє збільшити метрологічну надійність ЗВТ.

Мета даної роботи - вдосконалення системи метрологічного обслуговування засобів вимірювальної техніки при виробництві авіаційних двигунів на основі досліджень залежності показників надійності засобів вимірювальної техніки від основних параметрів МО 3ВТ.

\section{1. Організація і модель систем метрологічного обслуговування засобів вимірювальної техніки}

Нехай на підприємстві існує Р типів робочих місць по виготовленню продукції, де використовуються М видів 3ВТ. 
Тоді загальні втрати від браку $\mathrm{C}^{\text {бр }}$ будуть залежати від $\mathrm{C}_{\mathrm{jk}}^{\text {бp }}$, що визначає внесок у $\mathrm{C}^{\text {бр }}$ втрати від браку на робочому місці к-го типу при використанні ЗВТ ј-го виду та від коефіцієнта вірогідності показань ЗВТ ј-го типу $\mathrm{K}_{\mathrm{Bj}}, \mathrm{j}=\overline{1, \mathrm{M}} ; \mathrm{k}=\overline{1, \mathrm{~K}}$.

Величина $\mathrm{C}_{\mathrm{jk}}^{\text {бp }}$ залежить від множини факторів: типу виробництва виробничої програми, технологічних процесів, складу основного й допоміжного устаткування i його компонування на виробничих площах, стратегії керування виробництвом і т. ін., тобто від організаційно-виробничої структури. Вивчення поводження величини $\mathrm{C}_{\mathrm{jk}}^{6 \mathrm{p}}$ - цілий самостійний напрямок, пов'язаний з аналізом організаційновиробничої структури підприємства, що виходять за рамки дійсної роботи. Для вирішення задач оптимізації параметрів метрологічного обслуговування ЗВТ з метою зниження загальних витрат на виробництво продукції можна вважати, що значення величин $\mathrm{C}_{\mathrm{jk}}^{\text {бp }} \epsilon$ вхідними даними, що характеризують типовий виробничий процес. При цьому допускається, що з боку виробничої системи на величини $\mathrm{K}_{\Gamma}, \mathrm{K}_{\mathrm{TB}}, \mathrm{K}_{\mathrm{B}}$ можуть бути накладені обмеження.

Як цільову функцію можна взяти суму втрат від браку й суму витрат на утримування і функціонування МО ЗВТ. Щоб обгрунтувати такий вибір цільової функції, варто зробити зауваження. Для цього уточнимо поняття втрат від браку. В загальному випадку всі витрати виробництва компенсуються $з$ прибутку від реалізації продукції. Оскільки вартість товару не може перевищити його споживчу вартість, значить незалежно від того, у яки цінах (договірних, централізовано або самостійно встановлюваних) реалізується продукція, ці ціни завжди обмежені зверху. Виробничі потужності підприємства й організація виробництва накладають обмеження на випуск продукції в одиницю часу. Таким чином, прибуток колективу підприємства обмежений.

Якщо на деякому робочому місці у виробі виникає брак, то або цей виріб не буду реалізовано, підприємство буде виплачувати штрафні санкції чи усувати брак за свій рахунок. Так чи інакше це еквівалентно втраті частини доходу від реалізації. Частка цих витрат, що доводиться на дане робоче місце й даний тип використовуваного ЗВТ, є втратами від браку. Наведені до одиниці часу ці втрати відповідають позначеним вище $\mathrm{C}_{\mathrm{jk}}^{\text {бp }}$. При цьому матеріальні витрати на випуск бракованої продукції компенсуються 3 доходів від реалізованої продукції. Таким чином, введення величини $\mathrm{C}_{\mathrm{jk}}^{\sigma \mathrm{p}}$ можна розглядати як витрати на виробництво бракованої продукції.

Відповідно до сказаного, задача визначення втрат від браку може бути сформульована в такий спосіб.

Нехай інтенсивність реалізації продукції виражається в грошових одиницях, що одержують в одинцю часу. При відсутності виробництва бракованих виробів позначимо їі $\mathrm{B}_{0}$. При наявності у виробах баку інтенсивність виручки $\mathrm{B}_{0}$ можна представити як $\mathrm{B}_{0}=\mathrm{B}_{\mathrm{p}}+\mathrm{B}_{\text {бр }}$, де $\mathrm{B}_{\mathrm{p}}$ - виручка від реа-

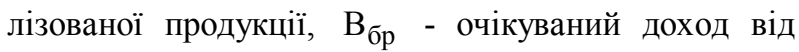
бракованих виробів, якби вони не містили браку. Частина $\mathrm{B}_{\text {бр }}$ пов'язана з використанням на робочих місцях ЗВТ з прихованими відмовами, є $\mathrm{C}^{\text {бр }}$. Отже, задачею визначення втрат від браку через дефектну роботу ЗВТ є визначення величини $\mathrm{C}^{\text {бp }}$, як частки потенційної виручки, недоотриманої внаслідок наявності у виробах браку через застосування ЗВТ 3 прихованими відмовами. Остаточним рішенням цієї задачі є визначення $\mathrm{C}_{\mathrm{jk}}^{\text {бp }}$ для відомої організаційновиробничої структури і формулювання обмежень на показники надійності ЗВТ - $\mathrm{K}_{\Gamma}, \mathrm{K}_{\mathrm{TB}}, \mathrm{K}_{\mathrm{B}}$.

Для визначення витрат на утримування системи МО ЗВТ розглянемо спочатку таку організацію МО ЗВТ, при якій всі перевірочні й ремонтні роботи виконуються усередині підприємства - замкнута система.

Перевірочні й ремонтні установки, приміщення які вони займають, а також самі ЗВТ є частиною основних фондів підприємства. Фахівці з перевірки і ремонтники $є$ трудовими ресурсами підприємства. У процесі виконання перевірочних і ремонтних робіт споживаються енергія й запасні покупні комплектуючі вироби. Це основний склад витрат на утримування і функціонування МО ЗВТ. Витрати покриваються 3 доходів від реалізації підприємством своєї продукції, так само як і втрати від браку. Отже, задача визначення витрат на утримування і функціонування МО ЗВТ складається у визначенні витрат по зазначених компонентах. Ці витрати складаються 3 амортизаційних відрахувань на реновацію ЗВТ, амортизаційних відрахувань на реновацію й ремонт перевірочних і ремонтних установок і приміщень, де перебувають самі установки, відрахувань на повну заробітну плату фахівців з перевірки і ремонту ЗВТ, прямих матеріальних витрат на проведення перевірочних ремонтних робіт і накладних витрат, податку на працівників. 
Таким чином, стосовно виробничих систем організація МО ЗВТ тісно пов'язана 3 організацією основного виробництва. При цьому показники технічної й метрологічної надійності взаємозалежні і впливають на якість роботи всієї виробничої системи. Метрологічна надійність КВ впливає на якість продукції, що випускається, технічна надійність - на тривалість виробничих циклів, тобто на продуктивність виробничої системи.

Оскільки основним об'єктом МО ЗВТ $є$ саме 3ВТ, покажемо основні стани, в яких воно може перебувати. Розглянемо модель МО, що має п'ять станів ЗВТ:

1) ЗВТ працездатний і застосовується за призначенням;

2) ЗВТ непрацездатний, але застосовується за призначенням (схована відмова);

3) ЗВТ працездатний і перевірясться;

4) ЗВТ непрацездатний і перевіряється;

5) ЗВТ в ремонті.

Для конкретних ЗВТ ці події утворять повну групу: вони $\epsilon$ взаємовиключними, і ймовірність знайти ЗВТ, хоча б в одному з них, дорівнюе 1 (інших станів для ЗВТ не існує).

Перехід із стану 1 у стан 2 характеризується виникненням у ЗВТ схованої відмови.

Переходи 1-3 і 2-4 здійснюються планово, за графіком проведення періодичних перевірок 3 періодом $\mathrm{T}_{\mathrm{n}}=\mathrm{T}_{\mathrm{mnn}}+\tau_{\mathrm{n}}$, де $\mathrm{T}_{\mathrm{mnn}}$ - проміжний інтервал; $\tau_{\mathrm{n}}$ - тривалість перевірки. Позначимо: $\mathrm{T}_{\mathrm{mp}}$ - математичне очікування міжремонтного інтервалу; $\mathrm{T}_{\amalg}$ - математичне очікування циклу ЗВТ між двома послідовними ремонтами; $\tau_{\text {очік }}$ - математичне очікування часу відновлення ЗВТ в черзі на ремонт; $\tau_{p}$ - математичне очікування часу відновлення ЗВТ в черзі на ремонт; $\tau_{\mathrm{B}}=\tau_{\text {очік }}+\tau_{\mathrm{p}}$ - математичне очікування часу відновлення ЗВТ в ремонті; $\mathrm{N}_{\mathrm{n}}$ - математичне очікування номера останньої перевірки, що починається до закінчення інтервалу $\mathrm{T}_{\mathrm{mp}}$; $\mathrm{t}^{\prime}$ - математичне очікування інтервалу часу від моменту завершення останньої перевірки до закінчення інтервалу $\mathrm{T}_{\mathrm{mp}} ; \mathrm{K}$ - номер перевірки від початку циклу ЗВТ.

Перехід 3-4 аналогічний переходу 1-2. Перехід 3-4 здійснюється наприкінці перевірки за умови, що не було прийнято помилкове рішення про наявність у ЗВТ схованої відмови. У противному випадку спостерігається перехід 3-5. Аналогічно перехід 4-2 здійснюється, якщо через помилку (пропуску відмови) користувачеві повертається ЗВТ зі схованою відмовою, у противному випадку - перехід 4-5 - прийнято вірне рішення.

Крім цього, можуть відбуватися переходи 1-5, $2-5,3-5,4-5$, якщо в 3ВТ виникає явна відмова. Явна відмова - це, як правило, раптова відмова, поява якої може встановити сам користувач ЗВТ.

Перехід 5-3 - ідеальне відновлення, перехід 5-4 відновлення зі схованою відмовою, не усуненою через помилки, допущені під час виконання ремонту,

Як параметри системи МО ЗВТ використовуються: $\mathrm{T}_{\text {п }}$ - період повторення перевірочних робіт; $\tau_{\mathrm{n}}$ - час виконання перевірки; $\tau_{\mathrm{B}}$ - час відновлення

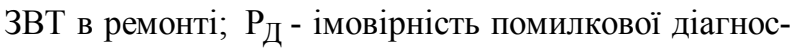
тики схованої відмови при перевірці; $\mathrm{P}_{\mathrm{CP}}$ - імовірність пропуску (невиявлення) схованої відмови при перевірці; $\beta_{\mathrm{p}}$ - імовірність повернення ЗВТ з ремонту зі схованою відмовою (передбачається, що явна відмова при ремонті усувається безумовно).

\section{2. Визначення зв'язку параметрів і надійності системи метрологічного обслуговування засобів}

Надійність МО ЗВТ при експлуатації, перш за все, залежить від параметрів системи МО ЗВТ.

Показники надійності ЗВТ визначаються не стільки абсолютними значеннями параметрів ЗВТ, скільки їхніми відносинами до наробки на явну відмову $\mathrm{T}_{я}$, а також залежать від відношення величин $\mathrm{T}_{\mathrm{c}}$ та $\mathrm{T}_{я}$. Щоб всі величини, що мають розмірність часу, виразити в одиницях $\mathrm{T}_{\text {я }}$, використаємо наступні перетворення: $\theta_{\mathrm{c}}=\frac{\mathrm{T}_{\mathrm{c}}}{\mathrm{T}_{\mathrm{g}}} ; \theta_{\Pi}=\frac{\mathrm{T}_{\Pi}}{\mathrm{T}_{\mathrm{g}}} ; \theta_{\mathrm{p}}=\frac{\mathrm{T}_{\mathrm{p}}}{\mathrm{T}_{\mathrm{g}}}$.

Визначмо залежність $\mathrm{K}_{\Gamma}, \mathrm{K}_{\mathrm{B}}, \theta_{\mathrm{p}}$ від параметрів метрологічного обслуговування: імовірністі помилкової діагностики при перевірці ( $\left.\mathrm{P}_{\text {Д }}\right)$ та імовірністі пропуску (невиявлення) відмови при перевірці $\left(\mathrm{P}_{\mathrm{CP}}\right)$ з допомогою алгоритму наведеного в [1].

В основі проведених розрахунків при аналізі метрологічної надійності ЗВТ лежить завдання деякої кількості вхідних даних, до яких відносяться $\theta_{\text {п }}, \theta_{\mathrm{c}}, \mathrm{P}_{\text {Д }}, \mathrm{P}_{\mathrm{CP}}$, які визначаються до початку розрахунків, що $\epsilon$ результатом статистичних розрахунків.

Величина $\mathrm{P}_{\text {Д }}$ (імовірність похибок діагностики при перевірці ЗВТ) визначається на основі аналізу якості проведення перевірочних робіт. Вона може бути задана в вигляді числового значення від 0 до 1 . Величина $\mathrm{P}_{\mathrm{CP}}$ (ймовірність прихованих відмов в ЗВТ після ремонту) визначається якістю ремонтних 
робіт і в залежності від їх рівня може бути визначена числовими значеннями від 0 до 1 . Значення $\theta_{\text {п }}$, $\theta_{c}$ - залежать від значення величини напрацювання на явну відмову $\mathrm{T}_{\text {я }}$, напрацювання на приховану відмову $\mathrm{T}_{\mathrm{c}}$ і міжперевірочного проміжку $\mathrm{T}_{\Pi}$.

Задамо:

$\mathrm{T}_{\Pi}=12$ міс.; $\mathrm{T}_{\mathrm{c}}=10,5$ міс.; $\mathrm{T}_{\mathrm{r}}=18$ міс.

$\theta_{\Pi}=0,666 ; \theta_{\mathrm{c}}=0,583$.

Таким чином, результатами таблиці 1 визначено вплив на показники надійності ЗВТ параметрів MO 3BT.

\section{Висновки}

Розглянуто організація підсистем метрологічного обслуговування засобів вимірювальної техніки (МО 3ВТ) на промислових підприємствах

Визначені основні показники надійності ЗВТ і параметри МО ЗВТ.

Одержані корисні для практичного використання залежності показників надійності засобів вимірювальної техніки від параметрів метрологічного обслуговування (імовірністі помилкової діагностики і імовірністі невиявлення відмови) при постійних значеннях інших параметрів, величини яких задані типовими для систем МО ЗВТ на промислових підприємствах.

\section{Література}

1. Метрологічне забезпечення контролю якості продукиії [Електронний ресурс] : монографія / В. У. Ігнаткін, Ю. М. Туз, К. М. Левківський, О. В. Томашевський ; за ред. В. У. Ігнаткіна. - Запоріж- жя : Запорізький національний технічний універсиmem, 2017. - 202 c. - Режим достуny: http://eir.zntu.edu.ua/handle/123456789/309. - 12.05.2018.

2. Ігнаткін, В. У. Моделювання проиесів метрологічного обслуговування засобів вимірювання [Текст] / В.У. Ігнаткін // Вісник двигунобудування. - 2014. - №1. - C. 161-167.

3. Ігнаткін, В. У. Коректування тривалості міжповірочних інтервалів засобів вимірювальної техніки за їх поточним технічним станом [Текст] / В. У. Ігнаткін, О. В. Томашевський // Авиационнокосмическая техника и технология. - 2015. - № 8(125). - C. 119-122.

\section{References}

1. Ihnatkin, V. U., Tuz, Yu. M., Levkivskyi, K. M., Tomashevskyi O. V. Metrolohichne zabezpechennia kontroliu yakosti produktsii [Metrological support of product quality control]. Zaporizhzhia, Zaporizkyi natsionalnyi tekhnichnyi universytet Publ., 2017. 202 p. Available at: http://eir.zntu.edu.ua/handle/123456789/309 (accessed 12.05.2018).

2. Ihnatkin, V. U., Tomashevskyi, O. V. Modeliuvannia protsesiv metrolohichnoho obsluhovuvannia zasobiv vymiriuvannia [Correction for calibration interval of measuring equipment at their current technical states]. Visnik dvihunobuduvannja, 2014, no. 1, pp. 161-167.

3. Ihnatkin, V. U. Korektuvannia tryvalosti mizhpovirochnykh intervaliv zasobiv vymiriuvalnoi tekhniky za yikh potochnym tekhnichnym stanom [Modeling of service metrological a means of measurements]. Aviacijno-kosmicna tehnika $i$ tehnologia - Aerospace technic and technology, 2015, no. 8(125), pp. 119-122.

Таблиця 1

Залежність показників надійності ЗВТ $\kappa_{\Gamma}, \kappa_{\mathrm{B}}, \theta_{\mathrm{p}}$ від параметрів МО ЗВТ

\begin{tabular}{|c|c|c|c|c|c|c|c|c|c|c|c|c|c|}
\hline \multirow{2}{*}{$\mathrm{P}_{\text {Д }}$} & \multicolumn{3}{|c|}{$\mathrm{P}_{\mathrm{CP}}=0,02$} & \multicolumn{3}{|c|}{$\mathrm{P}_{\mathrm{CP}}=0,04$} & \multirow{2}{*}{$\mathrm{P}_{\mathrm{CP}}$} & \multicolumn{3}{|c|}{$\mathrm{P}_{\text {Д }}=0,02$} & \multicolumn{3}{|c|}{$\mathrm{P}_{\text {Д }}=0,08$} \\
\hline & $\mathrm{K}_{\Gamma}$ & $\mathrm{K}_{\mathrm{B}}$ & $\theta_{\mathrm{p}}$ & $\mathrm{K}_{\Gamma}$ & $\mathrm{K}_{\mathrm{B}}$ & $\theta_{\mathrm{p}}$ & & $\mathrm{K}_{\Gamma}$ & $\mathrm{K}_{\mathrm{B}}$ & $\theta_{\mathrm{p}}$ & $\mathrm{K}_{\Gamma}$ & $\mathrm{K}_{\mathrm{B}}$ & $\theta_{\mathrm{p}}$ \\
\hline 0 & 0,401 & 0,317 & 0,562 & 0,382 & 0,317 & 0,550 & 0 & 0,350 & 0,098 & 0,602 & 0,369 & 0,250 & 0,588 \\
\hline 0,1 & 0,395 & 0,232 & 0,575 & 0,371 & 0,279 & 0,582 & 0,1 & 0,360 & 0,098 & 0,596 & 0,378 & 0,250 & 0,580 \\
\hline 0,2 & 0,386 & 0,099 & 0,590 & 0,371 & 0,232 & 0,588 & 0,2 & 0,367 & 0,097 & 0,590 & 0,411 & 0,250 & 0,572 \\
\hline$\overline{0,3}$ & 0,367 & 0,008 & 0,608 & 0,355 & 0,098 & 0,633 & 0,3 & 0,374 & 0,097 & 0,584 & 0,400 & 0,250 & 0,564 \\
\hline 0,4 & 0,34 & $10^{-8}$ & 0,629 & 0,333 & $10^{-5}$ & 0,615 & 0,4 & 0,382 & 0,096 & 0,578 & 0,420 & 0,250 & 0,547 \\
\hline 0,5 & 0,307 & $10^{-9}$ & 0,654 & 0,303 & $10^{-6}$ & 0,633 & 0,5 & 0,391 & 0,096 & 0,572 & 0,440 & 0,250 & 0,531 \\
\hline 0,6 & 0,264 & - & 0,675 & 0,264 & $10^{-8}$ & 0,654 & 0,6 & 0,399 & 0,093 & 0,566 & 0,455 & 0,250 & 0,522 \\
\hline 0,7 & 0,130 & - & 0,682 & 0,212 & - & 0,720 & 0,7 & 0,408 & 0,090 & 0,560 & 0,470 & 0,250 & 0,515 \\
\hline 0,9 & 0,04 & - & 0,696 & 0,090 & - & 0,801 & 0,9 & 0,420 & 0,060 & 0,547 & 0,499 & 0,250 & 0,490 \\
\hline
\end{tabular}


Надійшла до редакиії 25.05.2018, розглянута на редколегії 27.07.2018

\section{ИССЛЕДОВАНИЕ ВЛИЯНИЯ НА НАДЕЖНОСТЬ СРЕДСТВ ИЗМЕРЕНИЙ ПАРАМЕТРОВ СИСТЕМЫ МЕТРОЛОГИЧЕСКОГО ОБСЛУЖИВАНИЯ}

\section{А. В. Томашевский, В. У. Игнаткин, Г. В. Снежной}

Рассмотрены организация производства и модель системы метрологического обслуживания средств измерительной техники (МО СИТ) на промышленных предприятиях со сложными технологическими процессами. Определены показатели технической и метрологической надёжности. Показано влияние оптимального выбора значений параметров системы метрологического обслуживания на уменьшение потерь от производства бракованной продукции. Получены зависимости показателей надёжности средств измерительной техники от основных параметров МО СИТ. Предложены рекомендации практического использования результатов исследования для предприятий, где изготавливается сложная продукция, в частности, при производстве авиационно-космической техники.

Ключевые слова: средства измерительной техники, система метрологического обслуживания, модель метрологического обслуживания, метрологическая надёжность, техническая надёжность, управление качеством продукции

\section{RESEARCH ON INFLUENCE RELIABILITY A MEANS OF MEASUREMENTS PARAMETERS SYSTEM OF SERVICE METROLOGICAL}

\section{A. V. Tomashevskyi, V. U. Yhnatkyn, G. V. Snizhnoi}

The organization of production and the model of a metrological maintenance system for measuring equipment at industrial enterprises with complex technological processes are considered. The organization of the metrological maintenance system for measuring equipment can be considered as providing a system of a general system for managing the quality of products of the production process. The system of metrological maintenance aimed at identifying defects in finished products and testing the quality of the product during its manufacture. The system of metrological maintenance of measuring equipment is considered as a closed system, that is, all verification and repair work is performed inside the enterprise. The parameters of the system are the period of repetition of the verification work; time of the check; recovery time in repair; probability of erroneous diagnosis; probability of skipping a latent failure during a check; probability of return from repair with hidden failure. Reliability of measuring equipment can be divided into technical and metrological reliability. When carrying out the studies, the availability factor and the reliability factor were used to characterize the technical reliability of measuring equipment. Metrological reliability was determined by the normalized index (the ratio of the mean time to repair to the average operating time for a clear failure). When performing calculations, the values of the probability of diagnostic errors are determined when testing the means of measuring equipment and the probability of hidden failures after repair. It is determined that the normalized metrological reliability index will increase with the probability of erroneous fault diagnosis and with the reduction of availability and reliability. With the increase in the probability of hidden failures after repair, the availability and reliability coefficients increase and the normalized metrological reliability index decreases. The obtained results are recommended for practical use in enterprises where complex products are manufactured, in particular, in the production of aerospace equipment.

Keywords: measuring equipment, metrological service system, metrological service model, metrological reliability, technical reliability, quality management

Томашевський Олександр Володимирович - канд. техн. наук, доцент, Запорізький національний технічний університет, Запоріжжя, Україна, e-mail: tmsh@email.ua.

Ігнаткін Валерій Устинович - д-р техн. наук, професор, зав. кафедри апаратури радіозв'язку, радіомовлення i телебачення, Дніпровський державний технічний університет, Кам'янське, e-mail: v.ignatkyn@ukr.net.

Сніжной Геннадій Валентинович - канд. фіз.-мат. наук, доцент, Запорізький національний технічний університет, м. Запоріжжя, Україна, e-mail: snow@zntu.edu.ua.

Tomashevskyi Oleksandr Volodymyrovych - Candidate of Technical Science, Associate Professor of Dept. of Microelectronics and Nanoelectronics, Zaporizhzhya National Technical University, Zaporizhzhya, Ukraine, e-mail: tmsh@email.ua.

Ignatkyn Valery Ustinovich - Doctor Technical Sciences, professor, head. Dept. of Radio Equipment, Broadcasting and Television, Dniprovsk State Technical University, Kamenskoe, Ukraine, e-mail: v.ignatkyn@ukr.net.

Snizhnoi Gennadii Valentinovich - Candidate of Physical and Mathematical Sciences, Associate Professor of Micro- and Nanoelectronics, Zaporizhzhya National Technical University, Zaporizhzhya, Ukraine, e-mail: snow@zntu.edu.ua. 